\title{
Percepção da administração tópica ocular de drogas: vaporização x gotas
}

\section{Topical drug administration perception: spray $x$ eyedrop}

Arlindo José Freire Portes ${ }^{1}$, Louise Pellegrino Gomes², Beatriz Lopes Moura Brasil do Amaral ${ }^{3}$, Lívio Massa ${ }^{4}$

\section{RESUMO}

Objetivo: Avaliar por questionário qual o nível de dificuldade para aplicação tópica de medicações oculares: vaporização ou gotas através da observação do paciente e qual método foi tecnicamente melhor utilizado para aplicação de drogas tópicas oculares. Métodos: A pesquisa foi realizada no decorrer de 2008 e 2009 no ambulatório de oftalmologia da Policlínica Ronaldo Gazolla. Foi utilizado um frasco de colírio e um de vaporizador com solução de carboximetilcelulose sódica a $0,5 \%$. Cada participante aplicou em um dos olhos a solução por vaporização ou instilação de gotas através de um processo randomizado. Foi perguntado ao paciente questões pré-formuladas sobre a praticidade de ambos os métodos. Resultados: Considerando o grau de dificuldade de administração tópica ocular: 36\% acharam difícil ou muito difícil a vaporização e $14 \%$ a instilação de colírio. As dificuldades descritas pelos pacientes foram relatadas por $64 \%$ dos pacientes para vaporização e por 34\% para aplicação de colírio ( $\mathrm{p}=0,0027)$. Já $42 \%$ dos pacientes necessitaram de mais de uma instilação para aplicação do colírio, enquanto $36 \%$ dos pacientes precisaram de mais de uma aplicação para que a droga vaporizada tivesse contato com o olho $(\mathrm{p}=0,49)$. Em $56 \%$ dos pacientes houve toque da ponta do colírio com os cílios, já com o vaporizador não houve toque $(\mathrm{p}=0,0001)$. Conclusão: A vaporização foi o método mais seguro para evitar a contaminação do frasco.A maior facilidade percebida pelos pacientes ao instilar o colírio em relação a vaporização foi devido a terem apoiado a ponta do frasco nos tecidos oculares.

Descritores: Volatilização; Administração tópica; Soluções oftálmicas; Lubrificantes; Olho/efeitos de drogas

\footnotetext{
1 Professor Adjunto de Oftalmologia da Universidade Estácio de Sá - Rio de Janeiro (RJ), Brasil;

${ }^{2}$ Acadêmica do $6^{\circ}$ ano do Curso de Medicina da Universidade Estácio de Sá - Rio de Janeiro (RJ), Brasil;

${ }^{3}$ Acadêmica do $6^{\circ}$ ano do Curso de Medicina da Universidade Estácio de Sá - Rio de Janeiro (RJ), Brasil;

${ }^{4}$ Acadêmico do $6^{\circ}$ ano do Curso de Medicina da Universidade Estácio de Sá - Rio de Janeiro (RJ), Brasil.
}

Trabalho realizado na Policlínica Ronaldo Gazolla da Universidade Estácio de Sá - Rio de Janeiro ( RJ), Brasil. 


\section{INTRODUÇÃO}

A o contrário dos tratamentos médicos baseados na ingestão de medicamentos por via oral, o uso correto de colírios depende de uma técnica de administração baseada em movimentos de coordenação motora fina associada à visão adequada ${ }^{(1)}$.

Muitos pacientes, notadamente os idosos, têm dificuldade em aplicar medicações oculares tópicas devido a não possuirem adequada coordenação motora ou visão de perto sem óculos ${ }^{(1)}$.

Vários estudos demonstraram que o uso incorreto de colírios pode acarretar o aumento da absorção sistêmica das drogas, com consequente maior toxicidade $^{(2)}$.

$\mathrm{O}$ uso incorreto ocorre quando se usa número excessivo de gotas por aplicação ou número excessivo de aplicações das gotas.

É comum o uso de gotas gerar sensações desagradáveis como queimação, ardência e lacrimejamento.Em virtude destas sensações, as crianças são de um grupo em que o uso de gotas representa um transtorno para a instituição de um tratamento, devido à sua pouca cooperação, exacerbada pela necessidade de manterem os olhos abertos para o colírio ser aplicado.

Alguns dos mais importantes fatores que levam os pacientes a não aderirem adequadamente ao tratamento com colírios podem estar relacionados à instilação incorreta destes, o que eleva o custo da terapêutica ${ }^{(3)}$.

O uso do medicamento sob a forma vaporizada pode facilitar o tratamento em: crianças, pacientes com altas ametropias, idosos, pós-operatórios, traumas oculares, etc. devido a menor necessidade de visão da ponta do colírio, da proximidade dos cílios e de coordenação motora ${ }^{(4)}$.

Há estudos que demonstraram a eficácia dos medicamentos quando aplicados na forma de vaporização. No Brasil apenas um estudo deste tipo foi publicado na Revista Brasileira de Oftalmologia por Tavares e Portes ${ }^{(4)}$ em 2006. Após extensa revisão bibliográfica nas bases de dados MedLine, LILACS e SciELO, não encontramos estudos nacionais ou internacionais sobre a percepção da aplicação tópica de drogas vaporizadas nos olhos.

Os objetivos deste trabalho foram:

a) Avaliar de acordo com questionário qual o nível de facilidade ou dificuldade para aplicação tópica de medicações oculares: vaporização x gotas;

b) Avaliar de acordo com a observação do paciente qual o método que foi utilizado com maior adequação técnica para aplicação de drogas tópicas oculares.

\section{Métodos}

A pesquisa foi realizada no no decorrer de 2008 e 2009 no Ambulatório de Oftalmologia da Policlínica Ronaldo Gazolla da Universidade Estácio de Sá - Rio de Janeiro (RJ), Brasil.

Foi utilizado um frasco de colírio de solução de lubrificante ocular de carboximetilcelulose sódica a $0,5 \%$ e um frasco de vaporizador previamente esterilizado com óxido de etileno contendo a mesma solução (procedimento realizado em centro cirúrgico).

No ambulatório havia uma cadeira e uma maca, de forma que os pacientes poderiam realizar a instilação, tanto quanto possível, da mesma forma que estivessem habituados a fazê-lo em seu próprio ambiente.

Para cada participante foi fornecido um frasco de colírio de solução lubrificante ocular de carboximetilcelulose sódica a $0,5 \%$ e solicitado que efetuasse a instilação do mesmo em um dos olhos previamente selecionado. Através de um processo randomizado por uma tabela pseudoaleatória do Excel só foram incluídos os pacientes que disseram saber instilar colírio nos olhos.

No outro olho foi solicitado que o participante aplicasse a solução de carboximetilcelulose sódica a $0,5 \%$ através do vaporizador.

Todo processo foi acompanhado pelos autores.

Após o processo foi perguntado ao paciente questões pré-formuladas sobre a praticidade de ambos os métodos.

A análise estatística foi realizada com auxílio da planilha Excel 2007 para confecção de tabelas e do programa Biostat 5.0 para cálculo da significância estatística.

\section{Aspectos éticos}

Esta pesquisa foi submetida ao Comitê de Ética em Pesquisa da Universidade Estácio de Sá.

\section{Resultados}

Dos 50 pacientes avaliados, $72 \%$ eram do sexo feminino com idade média de 50,94 \pm 18,16 anos.

Em relação ao grau de dificuldade de administração tópica ocular, $36 \%$ acharam difícil ou muito difícil a vaporização e $14 \%$ a instilação de colírio. Em contrapartida, $70 \%$ acharam fácil ou muito fácil realizar a instilação do colírio e $42 \%$ a vaporização (Tabela 1).

As dificuldades descritas pelos pacientes para a aplicação tópica ocular foram relatadas por $64 \%$ dos 
pacientes para vaporização e por $34 \%$ para aplicação de colírio $(\mathrm{p}=0,0027)$.

A maior dificuldade dos pacientes estudados era "acertar o olho" tanto em relação ao colírio quanto em relação à vaporização (Tabela 2 ).

Noventa por cento (90\%) das vaporizações realizadas atingiram o globo ocular na primeira administração, enquanto $88 \%$ das gotas do colírio instiladas atingiram o olho na primeira aplicação $(\mathrm{p}=0,74)$.

Em $42 \%$ dos pacientes observados houve necessidade de uma nova aplicação do colírio, o que ocorreu também em $36 \%$ dos olhos que sofreram vaporização $(\mathrm{p}=0,54)$.

Em relação ao número de aplicações, $42 \%$ dos pacientes necessitaram de mais de uma instilação para aplicação tópica do colírio, enquanto $36 \%$ dos pacientes precisaram de mais de uma aplicação para que a droga vaporizada tivesse contato com o olho $(\mathrm{p}=0,49)$ ( Tabela 3 )

Em $56 \%$ dos pacientes houve toque da ponta do colírio com os cílios, enquanto com o vaporizador não houve toque $(\mathrm{p}=0,0001)$.

\section{Discussão}

Após extensa revisão bibliográfica em bancos de dados nacionais e internacionais, como Medline, Lilacs e Scielo, não observamos nenhum estudo comparando a percepção do paciente sobre a instilação de colírios em relação à vaporização de drogas tópicas oculares.

Tavares et al. ${ }^{(4)}$ em 2006 compararam a eficácia da midríase produzida por vaporizador ou gota com o uso de tropicamida a $1 \%$ em crianças de 5 a 10 anos e não encontraram diferença clínica e estatisticamente significativa da midríase causada pela vaporização em relação a gota. Seria útil que se avaliasse também a percepção do paciente quanto a facilidade e praticidade do uso da vaporização em relação à instilação de gotas, pois esta percepção afeta a fidelidade ao tratamento e indica o quanto o modo de administração pode ser feito corretamente possibilitando a eficácia.

Solomon et al..$^{(5)}$ ressaltaram em seu estudo, em 2003, a importância de uma instrução correta de como instilar colírios após observar lesão conjuntival pelo contato não intencional da ponta do tubo com os olhos em 12 pacientes avaliados com queixa de dor e hiperemia ocular aguda. Em nosso trabalho, observamos que nos olhos em que foram aplicados o colírio houve uma maior quantidade de toques da ponta do frasco com o globo ocular do que nos olhos com vaporizador ( $\mathrm{p}=0,0001)$.

No trabalho de Dietlein et al. ${ }^{(1)}$ realizado em 2008,
Tabela 1

\section{Grau de dificuldade da administração tópica ocular de drogas}

\begin{tabular}{ccc}
\hline $\begin{array}{c}\text { Grau de } \\
\text { dificuldade }\end{array}$ & $\begin{array}{c}\text { Colírio } \\
(\%)\end{array}$ & $\begin{array}{c}\text { Vaporização } \\
(\mathbf{\%})\end{array}$ \\
\hline 1 & 8 & 10 \\
2 & 62 & 32 \\
3 & 16 & 22 \\
4 & 10 & 26 \\
5 & 4 & 10 \\
Total & $\mathbf{1 0 0}$ & $\mathbf{1 0 0}$ \\
\hline
\end{tabular}

1- muito fácil; 2- fácil; 3- nem fácil nem difícil; 4- difícil; 5- muito difícil

Tabela 2

\section{Dificuldades apresentadas pelos pacientes na} administração tópica de medicações

\begin{tabular}{lcccc}
\hline Dificuldade & \multicolumn{2}{c}{ Colírio } & \multicolumn{2}{c}{ Vaporização } \\
& n & \% & n & \% \\
\hline Acertar o olho & 13 & 26 & 9 & 18 \\
Piscar & 4 & 8 & 0 & 0 \\
Assusta & 1 & 2 & 4 & 8 \\
Grande quantidade & 1 & 2 & 4 & 8 \\
\hline
\end{tabular}

Um paciente pode ter referido mais de uma dificuldade

Tabela 3

Número de aplicações tópicas necessárias até a droga instilada atingir o olho

\begin{tabular}{ccc}
\hline $\begin{array}{c}\text { Número } \\
\text { de aplicações }\end{array}$ & $\begin{array}{c}\text { Colírio } \\
(\mathbf{\%})\end{array}$ & $\begin{array}{c}\text { Vaporização } \\
(\mathbf{\%})\end{array}$ \\
\hline 1 & 58 & 64 \\
2 & 34 & 34 \\
3 & 8 & 2 \\
Total & $\mathbf{1 0 0}$ & $\mathbf{1 0 0}$ \\
\hline
\end{tabular}

$68 \%$ dos pacientes que usavam um container lesavam a conjuntiva ou córnea. O risco de lesão tinha relaçao inversamente proporcional a acuidade visual do melhor olho dos pacientes. Logo, pacientes idosos tiveram maiores problemas na administração de containers e o sucesso da aplicação também poderia depender de uma experiência prévia com o uso desse tipo de frasco

Segundo Höfling-Lima et al. ${ }^{(6)} \mathrm{em}$ um estudo realizado em 2001 com 127 frascos de colírios com soro autólogo dos pacientes, 76,03\% apresentaram contaminação após o término do conteúdo do frasco devido ao toque da ponta do colírio com tecidos oculares. Os principais microrganismos encontrados foram: 
Staphylococcus coagulase-negativo (35,86\%), Alcaligenes sp (21,73\%), Klebsiella sp (20,65\%),Bacillus $s p(9,78 \%)$ e outras bactérias $(11,94 \%)$, o que mostrou que a contaminação pode ocorrer por microrganismos presentes na margem palpebral e conjuntiva por contato direto no momento de instilação. É importante ressaltar que no frasco do colírio não havia conservantes junto com o soro autólogo. Em nosso trabalho, observamos que a aplicação de drogas vaporizadas evita o contato da ponta do aplicador com a conjuntiva. Evitando assim a contaminação que foi demonstrada no estudo de Höfling-Lima.

No presente estudo, a maioria dos pacientes instilou o colírio erroneamente, permitindo o contato da ponta do frasco com os cílios ou utilizando o canto medial do olho como anteparo para realizar a aplicação. Isto pode explicar porque o colírio foi considerado de mais fácil aplicação.

Observamos que a vaporização é uma forma de administração de drogas oculares menos complicada que o método proposto por Morlet et al. ${ }^{(7)}$ no ano de 1997, que permite que o paciente instile o medicamento corretamente sem realizar o contato com o olho e sem necessitar de algum objeto de apoio. $\mathrm{O}$ artigo explica que com frasco de colírio de cabeça para baixo, o polegar deve estabilizar o frasco ao usar a testa como anteparo, enquanto a outra mão retrai a pálpebra inferior para que a gota atinja a superfície ocular.

Grande parte dos pacientes relatou maior dificuldade com a vaporização por não estarem acostumados com este ato, sugeriram que o auxílio de um espelho seria necessário para melhor localização do olho para a aplicação. A dificuldade relatada em pressionar o vaporizador, pela força excessiva a ser utilizada, explica-se pelo fato de que o nosso dispositivo não foi calibrado para aplicação de medicamentos oculares e sim adaptado para esta situação.

Em 2005 Muller et al. ${ }^{(8)}$ também questionaram em seu estudo a força necessária para aplicação do medicamento por um dispositivo de vaporização e a quantidade excessiva de substância vaporizada. Testes realizados in vitro compararam a força necessária para a instilação de colírios e para o ato de vaporização. A uma distância de $3 \mathrm{~cm}$ o vaporizador teve um efeito de força mecânica mais favorável do que as gotas para evitar o desperdício.

Encontramos na literatura outras possibilidades de administração de drogas oculares para ajudar o paciente a administrar de maneira correta, Overaker et al. ${ }^{(9)}$ publicaram em 1999 a criação de um novo tipo de frasco de colírio que pode ser instilado com o paciente com a cabeça na posição vertical. O dispositivo deve ser apoiado na bochecha do paciente e deste emerge um tubo cuja ponta é angulada para baixo de forma que ao apertar o frasco a gota cai de cima para baixo sem haver necessidade de virar o frasco.

\section{ConClusão}

A vaporização foi aplicada corretamente pela maioria dos pacientes, não houve nenhum contato do vaporizador com os tecidos oculares, método mais seguro para evitar a contaminação do frasco.

A maior facilidade percebida pelos pacientes ao instilar o colírio em relação a vaporização deveu-se ao fato de terem apoiado a ponta do frasco nos tecidos oculares no canto medial dos olhos.

\section{Abstract}

Objective: Evaluate how difficult it is to apply ocular topical medications based on patient observation and answers to a questionnaire. Eye drops were compared to vaporization. Methods: The study was performed in 2008 and 2009 in Policlinica Ronaldo Gazolla ophthalmological ambulatory. An eyedropper and a vaporizer with carboximetilcelulose $0,5 \%$ were used. Each individual tested applied randomly on one of their eyes an eye drop or vaporization. The patients had to answer questions about the practice concerning both forms of topical eye drug application. Results: $36 \%$ informed that it was difficult or very difficult to vaporize and $14 \%$ to use eye drops. Problems described by patients were considered by $64 \%$ for vaporization and by $34 \%$ for topical eye drop use ( $p=$ 0,0027). $42 \%$ of the patients needed more than one eye drop application to have eye drop contact, while $36 \%$ of the patients needed more than one application of vaporization in order to get drug eye contact ( $p=$ $0,49)$. In $56 \%$ of patients there were an eyedropper tip contact with cilia, however there was not contact when the medicine was vaporized ( $p=0,0001)$. Conclusion: Vaporization was the safest method to avoid topical ocular drug contamination by manipulation; the greater facility noticed for patients when they administered eye drops was achieved using eye tissues as an eyedropper support.

Keywords: Volatilization; Administration, topical; Ophthalmic solutions; Lubricants ; Eye/drug effects 


\section{ReferêNCIAS}

1. Dietlein TS, Jordan JF, Luke C, Schild A, Dinslage S, Krieglstein GK. Self-application of single-use eyedrop containers in an elderly population: comparisons with standard eyedrop bottle and with younger patients. Acta Ophthalmol. 2008; 86(8): 856-9.

2. Vaidergorn, PG, Malta RFS, Borges AS, Menezes MDR, Trindade ES, Santiago JBN. Técnica da instilação de colírios em pacientes portadores de glaucoma crônico. Arq Bras Oftalmol. 2003; 66(6):865-9.

3. Stillitano IG, Lima MG, Ribeiro MP, Cabral J, Brandt CT. Impacto econômico do custo de colírios no tratamento do glaucoma. Arq Bras Oftalmol. 2005; 68(1): 79-84.

4. Tavares MO, Portes AJF. Efeito midriático da tropicamida a 1\%: vaporização x gota, Rev Bras Oftalmol. 2006; 65(1):7-12.

5. Solomon A, Chowers I, Raiskup F, Siganos CS, Frucht-Per J. Inadvertent conjunctival trauma related to contact with drug container tips: A masquerade syndrome. Ophthalmology. 2003; 110(4):796-800.
6. Höfling-Lima AL, Lima AS, Batistoso JA, Kawamura D, Chalita MRC, Alves LS, Farah ME. Contaminação de frascos de colírios de soro autólogo. Arq Bras Oftalmol. 2001; 64 (1): 63-5.

7. Morlet N, Kelly M, Morlet GC. A method of drop administration, Ophthalmic Surg Lasers. 1997; 28(8): 687-9.

8. Muller F, Wagner M, Neubert RH. Comparative in vitro investigation of the forces exerted by eye drops and eye spray. Pharmazie. 2005; 60(8): 630-1.

9. Overaker RF, Dodge BC, Epstein DL. A new eyedrop dispensing bottle. Am J Ophthalmol. 1999;128(3): 368-70.

\author{
Endereço para Correspondência: \\ Arlindo Portes \\ Rua Riachuelo, $n^{\circ} 43$ - Lapa \\ CEP 20230-010 - Rio de Janeiro - RJ \\ e-mail: portes@uol.com.br
}

